\title{
ChemComm
}

Check for updates

Cite this: Chem. Commun., 2021, 57,11084

Received 15th June 2021,

Accepted 17th September 2021

DOI: $10.1039 / \mathrm{d} 1 \mathrm{cc} 03160 \mathrm{k}$

rsc.li/chemcomm

\section{Two-photon ESIPT-based fluorescent probe using 4-hydroxyisoindoline-1,3-dione for the detection of peroxynitrite $\dagger$}

\author{
Luling Wu, (D) $\ddagger^{a}$ Xue Tian, (D) $\ddagger^{a}$ Dong Joon Lee, Juyoung Yoon, (D) \\ Chang Su Lim, ${ }^{\star b}$ Hwan Myung Kim (iD ${ }^{\star b}$ and Tony D. James (D)*ad
}

\begin{abstract}
Excited-state intramolecular proton transfer (ESIPT)-based fluorophores with two-photon excitation fluorescence (TPEF) are rare. Our aim with this research was to develop ESIPT-based fluorophores exhibiting TPEF. Herein, we used 4-hydroxyisoindoline-1,3-dione as a scaffold to develop a two-photon fluorescent probe BHID-Bpin, for the detection of peroxynitrite $\left(\mathrm{ONOO}^{-}\right)$. BHID-Bpin exhibits excellent selectivity, sensitivity, and fast response towards $\mathrm{ONOO}^{-}$in PBS buffer solution $(10 \mathrm{mM}, \mathrm{pH}=7.40)$. Additionally, BHID-Bpin displays high photo-stability under two-photon irradiation at $750 \mathrm{~nm}$. Furthermore, the probe can image endogenous $\mathrm{ONOO}^{-}$in HeLa cells and exogenous $\mathrm{ONOO}^{-}$in rat hippocampal slices at a depth of $110 \mu \mathrm{m}$.
\end{abstract}

Peroxynitrite $\left(\mathrm{ONOO}^{-}\right)$is formed by the combination of nitric oxide (NO) and superoxide anion radical $\left(\mathrm{O}_{2}{ }^{-}\right)$under diffusion control without enzymatic catalysis. ${ }^{1-3}$ It acts as a strong reactive nitrogen species (RNS) which can react with wide array of critical bioactive species, such as proteins, nucleic acids, lipids, and transition-metal enzyme centers. ${ }^{4}$ The concentrations of $\mathrm{ONOO}^{-}$in vivo vary and have been estimated to be around $50-100 \mu \mathrm{M},{ }^{5}$ with concentrations up to $500 \mu \mathrm{M}$ having been reported in macrophages. ${ }^{6}$ In addition, hydrogen peroxide $\left(\mathrm{H}_{2} \mathrm{O}_{2}\right)$ is an important reactive oxygen species (ROS), which has a key role in physiological processes, including host defense, cell proliferation, cell growth, and signaling pathways. ${ }^{7-9}$ Previous studies have revealed that $\mathrm{H}_{2} \mathrm{O}_{2}$ can be endogenously produced in various cells and tissues via the activation of NADPH oxidase. ${ }^{10,11}$ The exact range of $\mathrm{H}_{2} \mathrm{O}_{2}$ varies depending

\footnotetext{
${ }^{a}$ Department of Chemistry, University of Bath, Bath, BA2 7AY, UK.

E-mail: t.d.james@bath.ac.uk

${ }^{b}$ Department of Energy Systems Research, Ajou University, Suwon 443-749, South Korea.E-mail: kimhm@ajou.ac.kr,su1222@ajou.ac.kr

${ }^{c}$ Department of Chemistry and Nano Science, Ewha Womans University, Seoul 03760, Republic of Korea

${ }^{d}$ School of Chemistry and Chemical Engineering, Henan Normal University,

Xinxiang 453007, P. R. China

$\dagger$ Electronic supplementary information (ESI) available. See DOI: 10.1039/ d1 1 cc03160k

\$ These authors contributed equally to this work.
}

on the cell line, and the intracellular homeostatic concentration ranges from 1 to approximately $100 \mathrm{nM} .{ }^{12}$ Excessive production of $\mathrm{ONOO}^{-}$and $\mathrm{H}_{2} \mathrm{O}_{2}$ are implicated in many pathological and physiological process associated with multiple oxidative stressrelated diseases, including neurodegenerative, inflammatory, and cardiovascular diseases as well as cancer. ${ }^{13-16}$ Therefore, methods for the detection of $\mathrm{ONOO}^{-} / \mathrm{H}_{2} \mathrm{O}_{2}$ in biological systems are of considerable importance for both early diagnosis of human disease and exploration of various pathophysiologies.

Fluorescence-based probes have been developed as powerful tools for the detection of $\mathrm{ONOO}^{-} / \mathrm{H}_{2} \mathrm{O}_{2}$, due to their good selectivity, high sensitivity, minimal invasiveness and convenience ${ }^{17-24}$ However, traditional one-photon probes require short excitation wavelengths ranging from ultraviolet to the visible range, limiting their use in tissues or animals owing to cellular autofluorescence, and shallow tissue penetration depth. ${ }^{19,25}$ Over the last three decades, two-photon microscopy (TPM) has attracted particular interest since it employs two photons of low energy, near-infrared light to excite a fluorescent dye. As such TPM can overcome the above-mentioned disadvantages to a certain extent. ${ }^{26-29}$ Excitedstate intramolecular proton transfer (ESIPT) fluorophores are attractive for developing reaction-based fluorescent probes. Since ESIPT fluorophores usually have large Stokes shift, high quantum yield, good photostability, and are biocompatible ${ }^{30-32}$ Two-photon ESIPT-based probes often incorporate: 2-(2'-hydroxyphenyl)benzimidazole (HBI) or 2-(2-hydroxyphenyl)-4(3H)-quinazolinone (HPQ) as a framework. For example, two ESIPT-based fluorescent probes (1 and 2) based on HBI and HPQ respectively as the core fluorophore are illustrated in Fig. 1. James et al. designed probe 1 by incorporating HBI and boronate ester. The probe enabled the imaging of endogenous $\mathrm{ONOO}^{-}$in RAW 264.7 macrophages and rat hippocampus tissue under two-photon excitation. ${ }^{33}$ Zhou and colleagues developed probe 2 which used HPQ as a scaffold for the detection of $\mathrm{H}_{2} \mathrm{O}_{2}$ in HeLa cells and muscle tissues under two-photon excitation at $720 \mathrm{~nm} \cdot{ }^{34}$ In order to extend the range of suitable ESIPT fluorophores for the construction of two-photon probes. Herein, the two-photon fluorescence properties of 2-butyl-4-hydroxyisoindoline-1, 


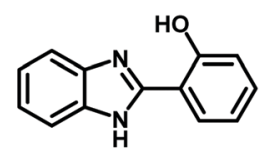

HBI

1

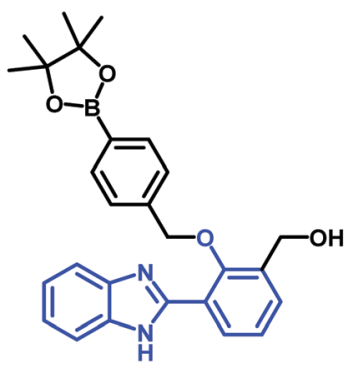

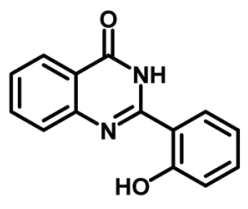

HPQ

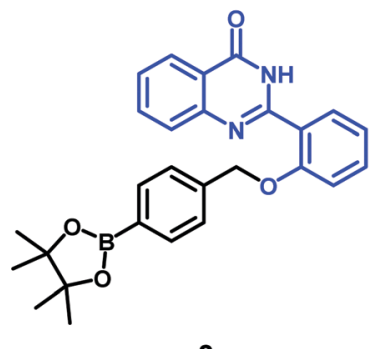

2
Fig. 1 Structures of previously reported two-photon ESIPT-based fluorescent probes. Where $\mathrm{HBI}$ and $\mathrm{HPQ}$ are used as the fluorophores.

3-dione (BHID, a 4-hydroxyisoindoline-1,3-dione (HID) derivative) are explored in the development of probe BHID-Bpin.

BHID-Bpin can be readily prepared and is non-fluorescent. However, upon addition of $\mathrm{ONOO}^{-} / \mathrm{H}_{2} \mathrm{O}_{2}$, the phenylboronic acid pinacol ester is oxidized by $\mathrm{ONOO}^{-} / \mathrm{H}_{2} \mathrm{O}_{2}$ which leads to the release of phenol moiety (Scheme 1). The BHID unit is fluorescent, since the ESIPT process is restored. The boronate pinacol ester can respond to both $\mathrm{ONOO}^{-}$and $\mathrm{H}_{2} \mathrm{O}_{2}$. However, it is much more sensitive to reaction with $\mathrm{ONOO}^{-}$than $\mathrm{H}_{2} \mathrm{O}_{2}$, because the enhanced nucleophilicity of $\mathrm{ONOO}^{-}$leads to a reaction rate $\sim 10^{6}$ times faster than that for $\mathrm{H}_{2} \mathrm{O}_{2} \cdot{ }^{35}$ Furthermore, different concentrations of $\mathrm{ONOO}^{-} / \mathrm{H}_{2} \mathrm{O}_{2}$ also affects the selectivity. ${ }^{22}$ Given the possible dual reactivity, we evaluated the concentration-dependent and time-dependent reactivity of BHID-Bpin towards both $\mathrm{H}_{2} \mathrm{O}_{2}$ and $\mathrm{ONOO}^{-}$in aqueous solutions. In addition, the probe was used to image $\mathrm{ONOO}^{-}$in cells and tissues with satisfactory results, demonstrating its practical applicability.

BHID-Bpin was synthesized using a simple two-step sequence (Scheme S1, ESI $\dagger$ ). Initially, BHID was synthesized utilizing commercially available 3-hydroxyphthalic anhydride and butylamine. Then a mixture of BHID, 4-bromomethylphenylboronic acid pinacol ester, and $\mathrm{K}_{2} \mathrm{CO}_{3}$ in dry DMF afforded BHID-Bpin in $61 \%$ yield. It is worth noting that 3-hydroxyphthalic anhydride has two sites that can be functionalized. The phenol which serves as a unit that can be used to block the ESIPT process upon attachment of a receptor. Additionally its anhydride unit can be used to construct dualresponsive probes or organelle-targeting probes by varying the amine used. With BHID-Bpin in hand we then evaluated the optical properties of the probe in PBS buffer solution $(10 \mathrm{mM}, \mathrm{pH}=7.40)$. The probe BHID-Bpin $(10 \mu \mathrm{M})$ exhibits no absorption peak, however, upon addition of $\mathrm{ONOO}^{-}(20 \mu \mathrm{M}) /$ $\mathrm{H}_{2} \mathrm{O}_{2}(95 \mu \mathrm{M})$, the probe displays a weak absorption at about $400 \mathrm{~nm}$ (Fig. S1 and S6, ESI $\dagger$ ). Therefore, excitation at $400 \mathrm{~nm}$ was used to investigate the fluorescence response of the probe towards $\mathrm{ONOO}^{-} / \mathrm{H}_{2} \mathrm{O}_{2}$ (Fig. 2 and 3). a)
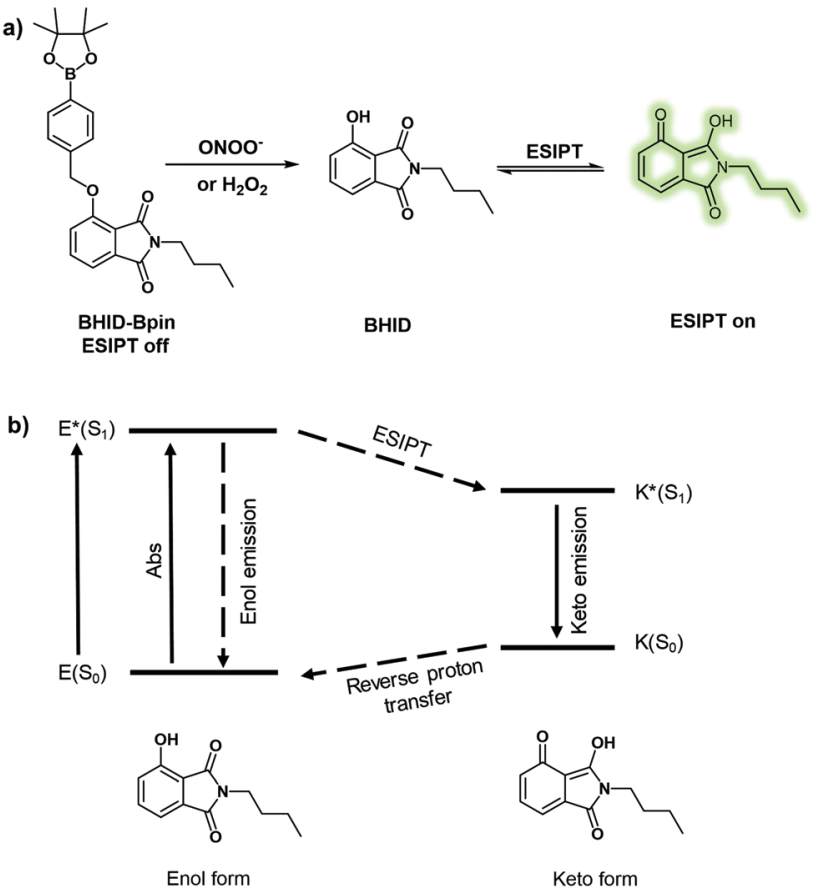

Scheme 1 (a) Reaction between probe BHID-Bpin and $\mathrm{ONOO}^{-} / \mathrm{H}_{2} \mathrm{O}_{2}$. (b) Diagram of ESIPT process of BHID.

As expected, BHID-Bpin displayed weak fluorescence due to the ESIPT process being blocked by the boronate ester moiety. However, with incremental addition of $\mathrm{ONOO}^{-}(0-20 \mu \mathrm{M}) / \mathrm{H}_{2} \mathrm{O}_{2}$ $(0-95 \mu \mathrm{M})$, the fluorescence spectra of BHID-Bpin displayed a continuous increase in emission intensity at $515 \mathrm{~nm}$ (Fig. 2a and 3a), that reached a plateaue when 2 equiv. of $\mathrm{ONOO}^{-} /$ 9.5 equiv. of $\mathrm{H}_{2} \mathrm{O}_{2}$ were added, causing a 31/29-fold enhancement in the fluorescence emission intensity (Fig. S2 and S7, ESI $\dagger$ ). Plots of the emission intensity at $515 \mathrm{~nm}$ versus concentration of $\mathrm{ONOO}^{-} / \mathrm{H}_{2} \mathrm{O}_{2}$ were used to determine the limit of detection to be $73 \mathrm{nM}$ for $\mathrm{ONOO}^{-}$and $221 \mathrm{nM}$ for $\mathrm{H}_{2} \mathrm{O}_{2}$ (linear equation: $y_{1}=448.67+1000.74 \times\left[\mathrm{ONOO}^{-}\right](\mu \mathrm{M}), R^{2}=0.999, y_{1}$ is the intensity at $515 \mathrm{~nm}$, Fig. $2 \mathrm{~b} ; y_{2}=632.99+331.02 \times\left[\mathrm{H}_{2} \mathrm{O}_{2}\right](\mu \mathrm{M})$, $R^{2}=0.986, y_{2}$ is the intensity at $515 \mathrm{~nm}$, Fig. $\left.3 \mathrm{~b}\right)$. To determine the selectivity towards $\mathrm{ONOO}^{-}$and $\mathrm{H}_{2} \mathrm{O}_{2}$, various interfering species were evaluated. As shown in Fig. S3 (ESI†), BHID-Bpin was particularly responsive towards $\mathrm{ONOO}^{-}$over $\mathrm{H}_{2} \mathrm{O}_{2}$, $\mathrm{ROO}^{\circ}$,
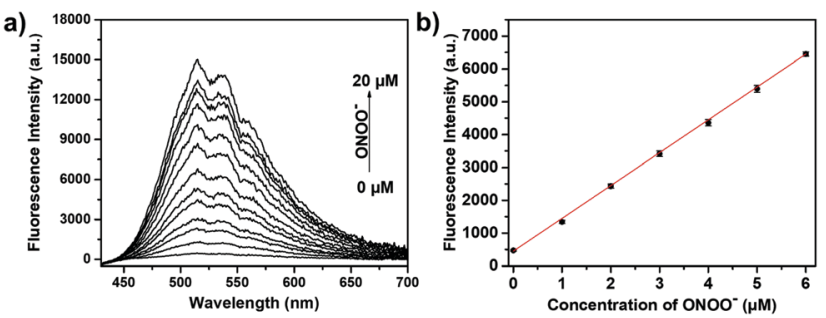

Fig. 2 (a) One-photon fluorescence spectra of BHID-Bpin $(10 \mu \mathrm{M})$ after the addition of various concentrations of $\mathrm{ONOO}^{-}(0-20 \mu \mathrm{M})$ in PBS buffer solution $(10 \mathrm{mM}, \mathrm{pH}=7.40)$ after $1 \mathrm{~min}$. $\lambda_{\mathrm{ex}}=400 \mathrm{~nm}$ (b) Linear relationship between fluorescence intensity of BHID-Bpin $(10 \mu \mathrm{M})$ and concentration of $\mathrm{ONOO}^{-}(0-6 \mu \mathrm{M})$ after $1 \mathrm{~min}$. $\lambda_{\mathrm{ex} / \mathrm{em}}=400 / 515 \mathrm{~nm}$. 

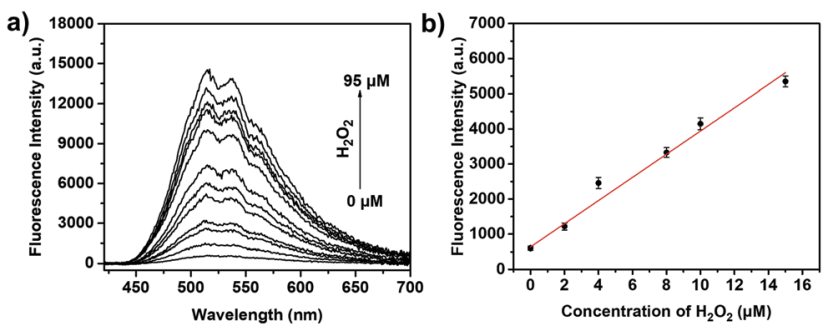

Fig. 3 (a) One-photon fluorescence spectra of BHID-Bpin $(10 \mu \mathrm{M})$ with addition of various concentrations of $\mathrm{H}_{2} \mathrm{O}_{2}(0-95 \mu \mathrm{M})$ in PBS buffer solution $(10 \mathrm{mM}, \mathrm{pH}=7.40)$ after $80 \mathrm{~min}$. $\lambda_{\text {ex }}=400 \mathrm{~nm}$. (b) Linear relationship between fluorescence intensity of BHID-Bpin $(10 \mu \mathrm{M})$ and concentration of $\mathrm{H}_{2} \mathrm{O}_{2}(0-15 \mu \mathrm{M})$ after $80 \mathrm{~min}$. $\lambda_{\text {ex/em }}=400 / 515 \mathrm{~nm}$.

$\cdot \mathrm{OH},{ }^{1} \mathrm{O}_{2}$, and $\mathrm{ClO}^{-}$when the solutions were incubated for 1 min. However, the existence of $\mathrm{ONOO}^{-}$or $\mathrm{H}_{2} \mathrm{O}_{2}$ could induce significant fluorescence enhancements of the probe BHID-Bpin when the solutions were incubated for $80 \mathrm{~min}$ and compared with other interfering species. The dynamic behaviour of probe BHID-Bpin was recorded in the presence of $\mathrm{ONOO}^{-} / \mathrm{H}_{2} \mathrm{O}_{2}$. As depicted in Fig. S5 and S9 (ESI $\dagger$ ). Upon addition of 2 equiv. of $\mathrm{ONOO}^{-} / 9.5$ equiv. of $\mathrm{H}_{2} \mathrm{O}_{2}$, a fluorescence enhancement was observed with maximum fluorescence observed at 1/80 min. These results indicated that probe BHID-Bpin has a much faster response and was more sensitive for $\mathrm{ONOO}^{-}$than $\mathrm{H}_{2} \mathrm{O}_{2}$.

To evaluate the practicability of probe BHID-Bpin under physiological conditions, the effect of $\mathrm{pH}$ on the fluorescence response of the probe in the absence and presence of $\mathrm{ONOO}^{-} /$ $\mathrm{H}_{2} \mathrm{O}_{2}$ at various $\mathrm{pH}$ values was determined. The fluorescence intensities of probe BHID-Bpin changed over a $\mathrm{pH}$ range from 3.00 to 12.00. In the presence of $\mathrm{ONOO}^{-} / \mathrm{H}_{2} \mathrm{O}_{2}$, there were notable changes in fluorescence of probe BHID-Bpin over a $\mathrm{pH}$ range from 7.40 to 9.00 , (Fig. S4 and S8, ESI $\dagger$ ) which indicated that the probe could be used to monitor $\mathrm{ONOO}^{-} / \mathrm{H}_{2} \mathrm{O}_{2}$ under physiological conditions. The fluorescence intensity at $515 \mathrm{~nm}$ decreased significantly when the $\mathrm{pH}$ was higher than 10 , probably due to inhibition of proton transfer by deprotonation of phenol groups. Decomposition of $\mathrm{ONOO}^{-}$in an acidic environment is likely responsible for the decreased emission intensities at low $\mathrm{pH}^{36}$ In addition, LC-MS experiments were performed to confirm the proposed fluorescence mechanism (Fig. S10-S13, ESI $†$ ).

Furthermore, the two-photon action cross section $(\Phi \delta)$ of BHID-Bpin and BHID was measured using rhodamine- $6 \mathrm{G}$ as a reference (Fig. S14, ESI $\dagger$ ). ${ }^{37}$ The maxima $\Phi \delta$ value of BHID-Bpin and BHID were calculated to be $0.7 \mathrm{GM}$ and $1.9 \mathrm{GM}$, respectively, under two-photon excitation at $750 \mathrm{~nm}$. Moreover, a cell counting kit-8 (CCK-8) method using HeLa cells was performed with different concentrations of BHID and BHID-Bpin to determine the cytotoxicity. As shown in Fig. S15 (ESI $\dagger$ ), both BHID and BHID-Bpin had negligible impact on cell survival. These data indicate that BHID-Bpin is suitable for measuring $\mathrm{ONOO}^{-}$concentrations in a cellular environment. In addition, no photobleaching occurred after BHID-Bpin was irradiated for $10 \mathrm{~min}$ under two-photon excitation at $750 \mathrm{~nm}$, which implied high photo-stability of the probe for real-time imaging (Fig. S16, ESI†). Next, BHID-Bpin was used to image exogenous $\mathrm{ONOO}^{-}$and $\mathrm{H}_{2} \mathrm{O}_{2}$ respectively using the same concentration $(300 \mu \mathrm{M})$ and incubation time $(20 \mathrm{~min})$ in HeLa cells. The two-photon imaging indicates that BHID-Bpin has higher sensitivity towards $\mathrm{ONOO}^{-}$ over $\mathrm{H}_{2} \mathrm{O}_{2}$ (Fig. S17, ESI $\dagger$ ). We then evaluated the use of probe BHID-Bpin for the detection $\mathrm{ONOO}^{-}$using other stimulus in live cells using TPM. TPM images of probe BHID-Bpin $(5 \mu \mathrm{M})$ labelled HeLa cells exhibit weak fluorescence intensity (Fig. S18a, ESI†). The two-photon excitation fluorescence (TPEF) intensity was markedly increased when the cells are treated with $300 \mu \mathrm{M}$ $\mathrm{ONOO}^{-}$(Fig. S18b, ESI $\dagger$ ). In addition, an increase in the intensity was observed when 3-morpholinosydnonimine (SIN-1), a wellknown $\mathrm{ONOO}^{-}$donor, was added (Fig. S18c, ESI $\dagger$ ). ${ }^{38,39}$ However, the fluorescence decreased upon pre-treatment with aminoguanidine (an inhibitor of nitric oxide synthase) ${ }^{40}$ or ebselen (an organoselenium compound, which is a known $\mathrm{ONOO}^{-}$scavenger that rapidly catalyzes the reduction of $\mathrm{ONOO}^{-}$) (Fig. S18e and $\mathrm{f}$ respectively, ESI $\dagger$ ). ${ }^{41}$ BHID-Bpin was then used to measure endogenous $\mathrm{ONOO}^{-}$. Using $50 \mathrm{ng} \mathrm{mL}{ }^{-1}$ interferon- $\gamma$ (IFN- $\gamma$ ) and $500 \mathrm{ng} \mathrm{mL} \mathrm{m}^{-1}$ lipopolysaccharide (LPS) resulted in the production of endogenous $\mathrm{ONOO}^{-},{ }^{42,43}$ leading to a significant enhancement in fluorescence, compared to the control group (Fig. S18, ESI $\dagger$ ). Next, we determined whether probe BHID-Bpin can be used to detect $\mathrm{ONOO}^{-}$in mice tissue (Fig. 4). TPM images of a portion of BHID-Bpin-labeled fresh rat hippocampal slices were obtained. The accumulated image at depths of 90-160 $\mu \mathrm{m}$ exhibited weak fluorescence intensity (Fig. 4a); however, the TPEF intensity of the image was markedly increased when the tissues were pre-treated with $50 \mu \mathrm{M}$ SIN-1 for $20 \mathrm{~min}$ (Fig. 4b). The images collected at a higher magnification clearly indicate the $\mathrm{ONOO}^{-}$levels in the individual cells (Fig. 4c-e). In addition, the TPEF intensity decreased upon treatment with $150 \mu \mathrm{M}$ ebselen for $40 \mathrm{~min}$

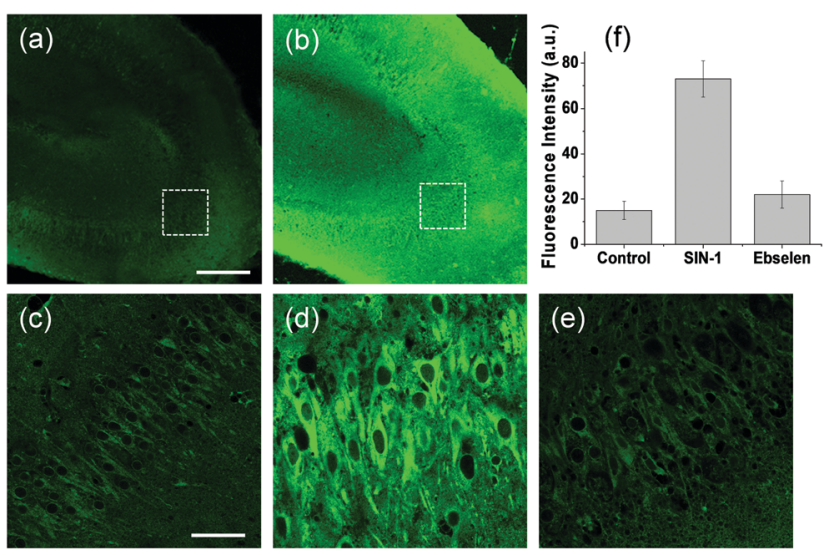

Fig. 4 TPM rat hippocampal slice images acquired after incubation of $20 \mu \mathrm{M}$ BHID-Bpin for $1 \mathrm{~h}$ and obtained at $\times 40$ magnification. ( $\mathrm{a}$ and $\mathrm{b}$ ) The TPM images are implemented by combining images in the $z$-direction, which correspond to depths of $90-160 \mu \mathrm{m}$ and detected in the

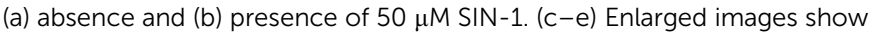
a white box part of panels $a$ and $b$ at a depth of $110 \mu \mathrm{m}$ and were acquired (c) before and ( $d$ and e) after the addition of (d) SIN-1 (50 $\mu \mathrm{M})$ for 20 min, (e) $150 \mu \mathrm{M}$ ebselen with $50 \mu \mathrm{M}$ SIN-1 for 40 min. (f) Average TPEF intensity in panels C-e. Images were acquired at the range of $400-600 \mathrm{~nm}$ upon excitation at $750 \mathrm{~nm}$. Scale bar: (a) 300 and (c) $50 \mu \mathrm{m}$, respectively. 
(Fig. 4e). These results confirm that BHID-Bpin can be used as a tool for the imaging of exogenous $\mathrm{ONOO}^{-}$in living systems.

In summary, we have developed a fluorescent probe, BHID-Bpin, where HID was used for the first time as part of an ESIPT framework to detect $\mathrm{ONOO}^{-}$using TPM. Our approach used a simple two-step synthetic route to prepare the two-photon activatable probe. More importantly, the probe was used to measure $\mathrm{ONOO}^{-}$in HeLa cells with low cytotoxicity. Furthermore, the probe exhibited good twophoton properties and could be used to image exogenous $\mathrm{ONOO}^{-}$ in rat hippocampal slices at a depth up to $110 \mu \mathrm{m}$. Thus, our probe can be regarded as a powerful imaging tool to investigate $\mathrm{ONOO}^{-}$in living biological systems. The success of BHID-Bpin in imaging $\mathrm{ONOO}^{-}$using two-photon excitation indicates that HID is suitable for the construction of novel ESIPT-based two-photon fluorescent probes. Finally, we anticipate that the short emission wavelengths of BHID can be overcome by employing BHID as a Förster resonance energy transfer donor. ${ }^{44}$

LW wishes to thank China Scholarship Council and the University of Bath for supporting his PhD work in the UK. XT wishes to thank the University of Bath for supporting her $\mathrm{PhD}$ work in the UK. We would like to thank the EPSRC and the University of Bath for funding. DJL, CSL and HMK thank the National Leading Research Lab Program of the National Research Foundation of Korea (NRF), funded by the Korean government (MSIP) (NRF-2019R1A2B5B03100278, NRF-2021R1C1C1013187), Center for Convergence Research of Neurological Disorders (NRF-2019R1A5A2026045). TDJ wishes to thank the Royal Society for a Wolfson Research Merit Award and the Open Research Fund of the School of Chemistry and Chemical Engineering, Henan Normal University for support (2020ZD01). NMR and Mass Spectroscopic (MS) Characterisation facilities were provided by the Material and Chemical Characterisation Facility $\left(\mathrm{MC}^{2}\right)$ at the University of Bath (http://go.bath.ac.uk/mc2). All data supporting this study are provided as ESI $\dagger$ accompanying this paper.

\section{Conflicts of interest}

There are no conflicts to declare.

\section{Notes and references}

1 J. S. Beckman, T. W. Beckman, J. Chen, P. A. Marshall and B. A. Freeman, Proc. Natl. Acad. Sci. U. S. A., 1990, 87, 1620-1624.

2 R. Radi, J. Biol. Chem., 2013, 288, 26464-26472.

3 G. L. Squadrito and W. A. Pryor, Chem.-Biol. Interact., 1995, 96, 203-206.

4 G. Ferrer-Sueta, N. Campolo, M. Trujillo, S. Bartesaghi, S. Carballal, N. Romero, B. Alvarez and R. Radi, Chem. Rev., 2018, 118, 1338-1408.

5 C. Szabó, H. Ischiropoulos and R. Radi, Nat. Rev. Drug Discovery, 2007, 6, 662-680.

6 O. Stachowiak, M. Dolder, T. Wallimann and C. Richter, J. Biol. Chem., 1998, 273, 16694-16699.

7 M. Reth, Nat. Immunol., 2002, 3, 1129-1134.

8 R. S. Balaban, S. Nemoto and T. Finkel, Cell, 2005, 120, 483-495.

9 M. Ushio-Fukai, Cardiovasc. Res., 2006, 71, 226-235.

10 J. D. Lambeth, Nat. Rev. Immunol., 2004, 4, 181-189.
11 M. T. Quinn, M. C. B. Ammons and F. R. DeLeo, Clin. Sci., 2006, 111, $1-20$.

12 H. Sies, Redox Biol., 2017, 11, 613-619.

13 P. Pacher, J. S. Beckman and L. Liaudet, Physiol. Rev., 2007, 87, 315-424.

14 G. Ferrer-Sueta and R. Radi, ACS Chem. Biol., 2009, 4, 161-177.

15 C. Szabó, H. Ischiropoulos and R. Radi, Nat. Rev. Drug Discovery, 2007, 6, 662-680.

16 X. Bai, K. K.-H. Ng, J. J. Hu, S. Ye and D. Yang, Annu. Rev. Biochem., 2019, 88, 605-633.

17 L. Wu, J. Liu, P. Li, B. Tang and T. D. James, Chem. Soc. Rev., 2021, 50, 702-734.

18 L. Wu, A. C. Sedgwick, X. Sun, S. D. Bull, X.-P. He and T. D. James, Acc. Chem. Res., 2019, 52, 2582-2597.

19 X. Tian, L. C. Murfin, L. Wu, S. E. Lewis and T. D. James, Chem. Sci., 2021, 12, 3406-3426.

20 D. Cheng, W. Xu, X. Gong, L. Yuan and X.-B. Zhang, Acc. Chem. Res., 2021, 54, 403-415.

21 Y. Li, X. Xie, X. Yang, M. Li, X. Jiao, Y. Sun, X. Wang and B. Tang, Chem. Sci., 2017, 8, 4006-4011.

22 L. Wu, J. Huang, K. Pu and T. D. James, Nat. Rev. Chem., 2021, 5, 406-421.

23 J.-S. Hu, C. Shao, X. Wang, X. Di, X. Xue, Z. Su, J. Zhao, H.-L. Zhu, H.-K. Liu and Y. Qian, Adv. Sci., 2019, 6, 1900341.

24 X. Xie, F. Tang, G. Liu, Y. Li, X. Su, X. Jiao, X. Wang and B. Tang, Anal. Chem., 2018, 90, 11629-11635.

25 G. Maulucci, G. Bačić, L. Bridal, H. H. Schmidt, B. Tavitian, T. Viel, H. Utsumi, A. S. Yalçın and M. De Spirito, Antioxid. Redox Signaling, 2016, 24, 939-958.

26 F. Helmchen and W. Denk, Nat. Methods, 2005, 2, 932-940.

27 W. R. Zipfel, R. M. Williams and W. W. Webb, Nat. Biotechnol., 2003, 21, 1369-1377.

28 H. M. Kim and B. R. Cho, Chem. Rev., 2015, 115, 5014-5055.

29 Y. L. Pak, S. J. Park, D. Wu, B. Cheon, H. M. Kim, J. Bouffard and J. Yoon, Angew. Chem., Int. Ed., 2018, 57, 1567-1571.

30 M. Nakazono, K. Saita, C. Kurihara, S. Nanbu and K. Zaitsu, J. Photochem. Photobiol., A, 2009, 208, 21-26.

31 W. Feng, S. Feng and G. Feng, Anal. Chem., 2019, 91, 8602-8606.

32 A. C. Sedgwick, L. Wu, H.-H. Han, S. D. Bull, X.-P. He, T. D. James, J. L. Sessler, B. Z. Tang, H. Tian and J. Yoon, Chem. Soc. Rev., 2018, 47, 8842-8880.

33 M. L. Odyniec, S.-J. Park, J. E. Gardiner, E. C. Webb, A. C. Sedgwick, J. Yoon, S. D. Bull, H. M. Kim and T. D. James, Chem. Sci., 2020, 11, 7329-7334.

34 L. Zhou, Y. Peng, Q. Wang and Q. Lin, J. Photochem. Photobiol., B, 2017, 167, 264-268.

35 A. Sikora, J. Zielonka, M. Lopez, J. Joseph and B. Kalyanaraman, Free Radical Biol. Med., 2009, 47, 1401-1407.

36 M. Kirsch, H.-G. Korth, A. Wensing, R. Sustmann and H. de Groot, Arch. Biochem. Biophys., 2003, 418, 133-150.

37 M. A. Albota, C. Xu and W. W. Webb, Appl. Opt., 1998, 37, 7352-7356.

38 X. Li, R.-R. Tao, L.-J. Hong, J. Cheng, Q. Jiang, Y.-M. Lu, M.-H. Liao, W.-F. Ye, N.-N. Lu, F. Han, Y.-Z. Hu and Y.-H. Hu, J. Am. Chem. Soc., 2015, 137, 12296-12303.

39 S. F. Peteu, R. Boukherroub and S. Szunerits, Biosens. Bioelectron., 2014, 58, 359-373.

40 R. B. R. Muijsers, E. van den Worm, G. Folkerts, C. J. Beukelman, A. S. Koster, D. S. Postma and F. P. Nijkamp, Br. J. Pharmacol., 2000, 130, 932-936.

41 A. Daiber, M.-H. Zou, M. Bachschmid and V. Ullrich, Biochem. Pharmacol., 2000, 59, 153-160.

42 N. M. Iovine, S. Pursnani, A. Voldman, G. Wasserman, M. J. Blaser and Y. Weinrauch, Infect. Immun., 2008, 76, 986-993.

43 A. H. Ding, C. F. Nathan and D. J. Stuehr, J. Immunol., 1988, 141, 2407-2412.

44 L. Wu, C. Huang, B. P. Emery, A. C. Sedgwick, S. D. Bull, X.-P. He, H. Tian, J. Yoon, J. L. Sessler and T. D. James, Chem. Soc. Rev., 2020, 49, 5110-5139. 